\title{
De Estado a Civil: As políticas de relações matrimoniais da casa imperial do Brasil e sua legitimação sucessória (1843-1944)
}

\author{
Adel Igor Romanov Pausini ${ }^{1}$
}

\begin{abstract}
Resumo: Em 1908 a renúncia do herdeiro do trono brasileiro segundo a Constituição de 1824 para casar fora do seio monárquico, torna-se o ponto inicial de sucessivas disputas de reconhecimento, anulação e legitimação de posições tradicionais e simbólicas em cenário republicano presidencialista. A política matrimonial se revela um indispensável instrumento na construção da rede de parentes, que confere relações, prestígio, legitimidade e poder, seja na condição régia ou após a sua queda. A situação cognática bilateral da Casa do Brasil se torna uma possibilidade em 1908, ainda que no campo simbólico, de modo que o período selecionado permite a clara visualização das rupturas e permanências na construção da política matrimonial na monarquia e na república. Partindo de fontes primárias como diários, cartas e bilhetes trocados no âmbito familiar e oficial, bem como, contratos de casamento, declarações e convenções, são constituintes da pesquisa documental, acrescida e cruzada com consistente bibliografia, sustentamos a tese de que mesmo após a queda da monarquia poucas rupturas são verificadas na política de casamentos, permanecendo no entanto as tensões, conflitos e disputas sucessórias se não pela condição régia já inexistente, pela condição de chefe ou líder do simbolismo monárquico tradicional de uma linhagem, na condição francesa ou brasileira.
\end{abstract}

Palavras-chave: Sucessão. Renúncia. Matrimônio. Casa do Brasil. Prestígio.

\footnotetext{
${ }^{1}$ Mestre em ciências sociais pela Pontifícia Universidade Católica de São Paulo, bolsa pesquisa Cnpq. Pesquisador doutoral da Universidade Lusófona de Humanidades e Tecnologias (Lisboa). Doutorando do Programa Interuniversitário em história da Universidade de Lisboa, Universidade de Évora, Universidade Católica Portuguesa e Instituto Universitário de Lisboa. Uma versão preliminar desse texto foi apresentada no VIII Seminário Nacional de Sociologia e Política realizado de 17 a 19 de maio de 2017 na UFPR.E-mail: adel.igor@hotmail.com ou adel.pausini@ics.ulisboa.pt
} 


\title{
From State to Civil: The policies of matrimonial relations of the imperial house of Brazil and its legitimation in succession (1843-1944)
}

\begin{abstract}
In 1908, the resignation of the heir to the Brazilian throne according to the Constitution of 1824 to marry outside the monarchical bosom becomes the starting point of successive disputes for the recognition, annulment and legitimation of traditional and symbolic positions in a presidential republican scenario. Marriage policy proves to be an indispensable instrument in the construction of the network of relatives, which confers relations, prestige, legitimacy and power, whether in the royal condition or after its fall. The bilateral cognitive situation of Casa do Brasil became a possibility in 1908, albeit in the symbolic field, so that the selected period allows a clear visualization of ruptures and permanences in the construction of marriage policy in the monarchy and in the republic. Starting from primary sources such as journals, letters and tickets exchanged within the family and official context, as well as marriage contracts, declarations and conventions, are constituents of documentary research, supplemented and crossed with a consistent bibliography, we maintain the thesis that even after the fall of the monarchy a few ruptures are verified in the policy of marriages, but the tensions, conflicts and successive disputes remain, if not by the regal condition no longer existent, by the condition of head or leader of the traditional monarchical symbolism of a lineage, in the French or Brazilian condition.
\end{abstract}

Keywords: Succession. Renounce. Marriage. House of Brazil. Prestige.

- Enviado em 01/05/2017

- Aprovado em 17/05/2017 


\title{
INTRODUÇÃO
}

É necessário lançar um olhar mais atento às políticas matrimoniais das casas régias durante o século XIX e XX. Ainda que modificações e rupturas existam neste percurso, certas permanências e continuidades são sensivelmente percebidas, e compreender o motivo de tais permanências possibilita a visualização de um quadro mais amplo, rico e geral sobre a conservação das tradições das casas monárquicas, sobretudo daquelas que se encontram alijadas do poder, mantendo-se mais conservadoras e pouco inovadoras em relação aquelas que se encontram no poder, e precisam necessariamente de se adaptar para manter tal situação.

Este texto se propõem a visualizar as disputas pelo direito sucessório do trono brasileiro durante o vigor da monarquia e após a sua queda, pelo viés da política matrimonial, tentando vislumbrar o quão estruturante é tal elemento para a tradição monárquica brasileira, como nos propõe o excerto de Pierre Bourdieu.

\begin{abstract}
É preciso se perguntar primeiro o que se encontra implicado no fato de definir um grupo pela relação genealógica que une seus membros e somente por isso, então tratar (implicitamente), o parentesco como condição necessária e suficiente da unidade de um grupo. De fato, levantar realmente a questão das funções das relações de parentesco ou, de modo mais brutal, da utilidade dos parentes, significa logo perceber que os usos do parentesco que podem ser chamados genealógicos são reservados às situações oficiais, nas quais desempenham uma função de ordenação do mundo social e de legitimação dessa ordem. (BOURDIEU, 2009 p. 274)
\end{abstract}

$\mathrm{Na}$ definição do antropólogo Claude Lévi-Strauss', o conceito de Casa tem origem no período medieval, onde era comumente utilizado para a compreensão de um composto de riquezas materiais e imateriais. As monarquias ocidentais modernas e contemporâneas possuem suas raízes exatamente no medievo, o que implica, sem desconsiderar as transacionalidades e especificidades de cada caso, uma certa herança, que sobretudo a casa francesa de Orléans e a casa portuguesa bragantina fazem questão de ressaltar e evidenciar, como elemento legitimador do seu poder nos marcos da dominação tradicional, segundo os conceitos de Max Weber.

São conhecidas, em diversos pontos do mundo, sociedades formadas por unidades que não se deixam definir como famílias, nem como clãs ou linhagens. (...) para compreendê- 
las, é preciso introduzir na nomenclatura etnológica a noção de "casa" (no sentido em que se fala de "casa nobre").

(LÉVI-STRAUSS, 1986 p. 186)

É exatamente com este sentido que nos apropriamos do conceito de casa, uma vez que o conceito de família, ainda que o de família nuclear de Margareth Mead, não seria suficiente para expressar os conflitos sucessórios vislumbrados na Casa imperial do Brasil. Neste sentido o conceito de família nuclear nos é interessante, quando estamos pensando de modo isolado a família imperial, ou seja, o imperador [chefe de Estado], sua esposa e filhos excluindo uma família alargada, a qual podemos inserir na nomenclatura Linhagem, ou seja, aqueles que possuem um ancestral em comum. Para tal, manejar de modo adequado estes conceitos: Linhagem, Casa e família, são fundamentais para facilitar a visualização das estratégias de construção da relação de parentesco e certa ciclicidade legitimada das casas que se articulam com o ramo brasileiro dos Bragança em matrimônio.

A construção da ramificação da Casa de Bragança por meio da ramificação binariamente dinasta da linhagem masculina de d. João VI de Portugal, reinante nos dois lados do atlântico, impõem questões peculiares a serem enfrentadas pela ramificação brasileira.

Se a legitimidade política e a ascendência real dos príncipes do Brasil possuía condição consolidada diante as monarquias europeias do século XIX, com base na primogenitura da casa bragantina, e na ascendência das dinastias Bragança, Habsburgo e Bourbon; questões como instabilidade política no interior do território; a situação peculiar de corte de tradições europeias instalada no continente americano; e a reconhecida pobreza financeira da casa imperial, eram empecilhos a serem enfrentados pela diplomacia brasileira.

A política matrimonial como nos coloca Perry Andersonii, se revela importante ferramenta da diplomacia e da política internacional no Antigo Regime, capaz de ampliar zonas de influência, território, selar tratados e acordos sem o dispendioso levantar de armas. Tal estratagema, também era capaz de estender e compartilhar o prestígio entre as monarquias envolvidas frente a aliança matrimonial.

Neste sentido, a primeira grande prova da diplomacia brasileira foi encontrar noiva em situação de igualdade de nascimento, portanto, uma princesa europeia, que aceitasse desposar o imperador viúvo e residir distante da Europa. A busca não era fácil, dada a má fama do imperador 
e ao elevado prestígio dos Habsburgo, casa a qual pertencia sua finada esposa. O aceite da proposta matrimonial ocorreu em 1828, Amélia de Leuchtenbergiii, a qual o título principesco pertencia a linha materna, casa de condição régia na Baviera ${ }^{i v}$.

O segundo desafio da diplomacia brasileira, foi contratar o casamento dos filhos legítimos do imperador d. Pedro I. Ainda que separadas e autônomas politicamente, a Casa imperial do Brasil e a Casa real portuguesa, estavam unidas pelo sangue dos irmãos Maria II e Pedro II, ambos membros da dinastia de Bragança. Em 1836 a rainha portuguesa desposa o príncipe Fernando de Saxe-Coburgo, sobrinho da duquesa de Kent, a quem o trono brasileiro não passa desapercebido em carta de 1838.

Sua Alteza Imperial [Januária, irmã de d. Pedro II] tem dezesseis anos, sua pessoa é das mais agradáveis e seu carater dos mais amáveis. Ela tem direito de sucessão ao trono. 0 imperador é um menor de doze anos, e é possível que ela seja um dia chamada ao trono do Brasil, agora, consolidado e baseado sobre princípios aristocráticos. Quanto ao casamento proposto, Sua Alteza Imperial, como esposa do príncipe Augusto Carlos de Saxe-Coburgo, partilharia sua posição na Áustriav, aportando-Ihe por apanágio o dote a que tem direito, e uma próxima parentela com a família imperial austríaca. (DEL PRIORE, 2007, p.43)

A intenção da mãe da rainha britânica era oferecer aliança ao Brasil com o Reino Unido e Bélgica, reinos os quais os Saxe-Coburgo ascenderam ao trono; reforçar a aliança com Portugal, que tinha por rei consorte um Saxe-Coburgo, e de apanágio oferecia relações de parentesco próximo com os Orléans, no trono da França. Por sua vez, a Casa de Saxe-Coburgo ganharia a possibilidade de ascensão ao trono brasileiro, e na pior das hipóteses, parentela próxima ao imperador austríaco garantida pelo casamento do príncipe Augusto de Saxe-Coburgo com a princesa Januária do Brasilvi.

Portanto a estratégia da duquesa de Kent buscava ampliar não apenas o prestígio da Casa de Saxe-Coburgo, mas também ampliar o poder de influência, capitaneando novos títulos e posições, como nos coloca o antropólogo Claude Lévi-Strauss, sendo esta intenção de união exogâmica, oposta a primeira opção de d. Pedro Il quando do casamento de suas filhas.

(...) o casamento exógamico serve par captar novos títulos e o casamento endógamo para evitar que, depois de adquiridos, eles saiam da casa. É então de boa estratégia utilizar conjuntamente ambos os princípios, consoante o tempo e a oportunidade, para maximizar os ganhos e minimizar as perdas. (Lévi-Strauss, 1979 p. 162) 
Mas o casamento com a linhagem Saxe, conforme nos indica Mary Del Priore estava fora de cogitação. A diplomacia brasileira, segundo Lilia Schwarcz vii ambicionava casamento com a mesma casa prestigiosa para o imperador e sua irmã, a princesa imperialviii, evitando assim o fracionamento político da casa do Brasil e a formação de partidos. O Casamento prestigioso que se almejava era com o império russo ou austríaco, mas o primeiro a se realizar ocorreu em 1843 entre a princesa Francisca e o príncipe de Joinville ${ }^{i x}$. Para o casamento imperial a diplomacia brasileira consegue apenas obter êxito na casa real das Duas-Sicílias, onde reinava a ramificação siciliana da Casa de Bourbon.

Os três casamentos realizados pela Casa imperial na década de 1840 ocorrem com ramificações da Casa de Bourbon, Bourbon-Orléans e Bourbon-Sicília, ambas de prestígio régio, mas a primeira instável politicamente no poder, e a segunda de reino pobre e pouco relevante no cenário internacional. Estas são as três parceiras que se repetem ciclicamente nos matrimonios da Casa do Brasil, Wittelsbach e as ramificações da Casa de Bourbon.

O casamento da segunda geração de príncipes do Brasil foi tratado diretamente pelo monarca, e não mais pela diplomacia brasileira. Estes apresentavam especial singularidade. Se tratava do casamento das duas únicas filhas do imperador d. Pedro II. O gênero das herdeiras do imperador implicava em escolha de príncipe capaz de respeitar a autonomia de sua esposa diante os assuntos do governo, bem como, não ser visto como estrangeiro que governava sua esposa nos assuntos de Estado, como um fantoche, e que pudesse colocar em situação duvidosa os interesses do império. Na hierarquia monárquica, Isabel teria posição superior ao marido, em uma clara inversão dos valores que vigoravam no período.

No século XIX, o casamento era o destino da maioria das mulheres ocidentais nascidas nas classes média e alta. A missão de vida da mulher consistia em prestar apoio, conforto e lealdade ao marido e em gerar e criar seus filhos. As mães educavam as filhas não só para contar com este destino, mas também aceitá-lo de bom grado (...) essencialmente o casamento era uma transação de bens arranjada pelos pais, segundo afirmavam os manuais (...). (BARMAM, 2005, p.78)

Isabel não seria a única mulher a dirigir uma monarquia no século XIX, esta se juntaria a outras mulheres como a rainha Vitória do Reino Unido, e sua tia Maria II de Portugal, ambas casadas com príncipes de Saxe-Coburgo. Se o matrimônio e a política matrimonial possuem relevância no cenário monárquico, o matrimônio de princesas herdeiras em ambiente patrilinear, 
ganha maior relevância, assim como coloca Lévi-Strauss ao estudar os Kwakiutl, em situação similar ao de Isabel.

\begin{abstract}
$\mathrm{Na}$ falta de herdeiros masculinos, e por vezes em concorrência com eles, as irmãs e as filhas podiam assegurar a transmissão dos títulos, ou de pleno direito, ou fazendo, como se diz então, 'a ponte e a prancha'. Tal como é a regra entre os Kwakiutl, elas transmitem então a seus filhos prerrogativas que esses recolhem, por seu intermédio, do avô materno deles. Talvez resulte disso o importante lugar que, em regimes ostensivamente patrilineares, é ocupado frequentemente pelo matrimônio. (LÉVI-STRAUSS, 1986 p.186)
\end{abstract}

Esta questão não passava desapercebida pelo imperador, que já em 1853 preferia para esposo de sua herdeira um de seus sobrinhos, membros da famíliax, o que poderia reduzir o desgaste do príncipe por ser estrangeiro. A preferência de d. Pedro II recaia inicialmente sobre os sobrinhos infantes de Portugal ${ }^{x i}$, hipótese logo refutada diante a possibilidade de interpretação de uma recolonização portuguesa do Brasil|xii; e o filho de sua irmã Franciscaxiii, que recusou desposar a prima brasileira.

A escolha do imperador não era fácil. É possível identificar dois grupos distintos dentre as monarquias europeias. As casas de tendências liberais ${ }^{\text {xiv }}$ como a de Bragança na Europa e América, casa de Saxe-Coburgo, Orléans e os Sabóia; e as casas de tendência mais conservadora como os Habsburgo e os Bourbon e suas ramificações a exceção do ramo francês [Orléans] ${ }^{\mathrm{xv}}$.

Em carta de setembro de 1863 ao cunhado príncipe de Joinville [Orléans], d. Pedro II o incube da tarefa de sondar possíveis pretendentes a mão das princesas do Brasil, deixando claro ao cunhado desejar que "(...) o marido deve ser católico, de sentimentos liberais, e não ser português, espanhol ou italiano, desejando que não seja austríaco(...)"xvi, voltando a insistir da predileção pelo sobrinho, filho de Joinville, ou no conde de Flandres, filho do rei Leopoldo da Bélgica, portanto, um Saxe-Coburgo, sobrinho de Augusto, o qual na década de 1830 a duquesa de Kent tentara casar com a irmã do imperador do Brasil.

A recusa do monarca brasileiro a genro português estava clara, situação semelhante á um príncipe espanhol, que poderia convulsionar as relações internacionais do Brasil com os países vizinhos, instáveis repúblicas, na maioria ex-colônias da Espanha. No mais, todos os demais príncipes indicados, a exceção dos portugueses e Sabóia, pertenciam a casas de tendência conservadora. 
Os dois príncipes sugeridos por Joinville e que tiveram a anuência do imperador foram Augusto de Saxe-Coburgo, filho da princesa de Orléans e do duque de Saxe-Coburgo, o mesmo que havia sido indicado para desposar Januária de Bragança; e seu primo Gaston de Orléans, filho da princesa de Saxe-Coburgo e do duque de Nemours [Orléans].

A princípio Gaston de Orléans era o pretendente da filha mais nova de d. Pedro II, e Augusto estava destinado a princesa herdeira, o que igualaria o ramo brasileiro da Casa de Bragança ao ramo português, o qual desde a morte da rainha Maria II, reinava a dinastia SaxeCoburgo e Bragança. O mesmo aconteceria no Brasil, caso o casamento tivesse ocorrido. A linhagem dos noivos era semelhante, ambos eram sobrinhos de Fernando II de Portugal, estavam ligados as Casas de Saxe-Coburgo e Orléans, ainda que, o primeiro fosse herdeiro de grande fortuna e de livre trânsito pelas cortes europeias condição distinta a do exilado Orléans, sobretudo na França napoleônica.

O consórcio de Isabel e Leopoldina ocorre em 1864 respectivamente com Gaston de Orleans e Augusto de Saxe-Coburgo. O primeiro casal logo no inicio do casamento enfrentou dificuldades que resultariam na queda de prestígio destes como a esterilidade atribuída a princesa herdeira, bem como o insucesso das viagens destes a Europa, onde não foram recebida na corte francesa ${ }^{x v i i}$ e inglesaxviii, o que maculava a imagem do jovem casal herdeiro, diante as expectativa da elite brasileira que almejava por prestígio. Por sua vez, a princesa Leopoldina, fixara residência em Viena, onde era comumente recebida com deferência na corte Habsburgo, assim como na francesa, inglesa e belga, territórios de livre circulação dos Saxe-Coburgo-Gotha, em clara oposição a situação de Isabel e Gastão. Mas o grande sucesso de Leopoldina e Augusto, residia nos filhos, em menos de seis anos de casamento, estes tiveram quatro filhos varões ${ }^{\text {xix }}$.

No mundo ocidental do século XIX, o destino da mulher era gerar e criar filhos. Conforme a opinião prevalecente, as qualidades que a tornam inferior ao homem eram exatamente as mesmas que a habilitavam a ser mãe. A pior coisa que podia acontecer a uma mulher era ficar 'solteirona' e não ser mãe. (BARMAN, 2005 p.168)

Em 1871 a princesa Leopoldina vem a falecer, deixando seus quatro filhos órfãos, enquanto a herdeira do império ainda não os tinha. Por proposição de d. Pedro II, os dois netos mais velhos se mudam para o Rio de Janeiro e ficam sob sua responsabilidade, eram eles herdeiros aparentes 
do império, e mais uma vez a possibilidade de ascensão dos Saxe-Coburgo a um trono bragantino, até 1875 quando nasce o primeiro filho de Isabel.

As regras de sucessão ao trono do Brasil eram claras. Mas Pedro de Saxe-Coburgo e Bragança, filho da princesa Leopoldina, alguns políticos e diplomatas cogitavam a hipótese de intervenção do imperador em favor do neto Coburgo. As possibilidades variavam desde a assunção deste como imperador, até uma possível regência deste até a maioridade de seu primo, o primogênito da princesa Isabel. As intenções eram claras. Afastar a possibilidade de assunção de Isabel do trono e, por consequência a elevação de prestigio de seu marido, Gaston de Orléans. Mas, ainda que o prestígio de Pedro de Saxe-Coburgo fosse elevado nas monarquias europeias, sobretudo a francesa e inglesa, e entre cientistas e intelectuais do Velho Mundo, sua proximidade com o avô d. Pedro II não afastou a princesa imperial de três regências, seguindo assim a normalidade prevista pela legislação brasileira.

Na década de 1880 a avó de Pedro de Saxe-Coburgo, Clementina de Orléans, passou a articular o casamento dele com uma princesa belga também Saxe-Coburgo, união endogâmica, em sistema de alianças semelhante ao que fora pretendido por $\mathrm{d}$. Pedro II na década de 1860 quando tencionava casar a princesa herdeira com o conde de Flandres [príncipe belga], aumentando assim, por certo, o prestígio do Coburgo no Brasil, em oposição aos tios, os quais segundo Del Priore, articulavam o casamento deste com uma princesa Orléans ${ }^{\mathrm{xx}}$, reduzindo assim possivelmente o distanciamento o qual Pedro de Saxe-Coburgo buscava tecer em relação aos tios, na busca de apoio a sucessão do monarca brasileiro.

Em carta de 1889 o príncipe Augusto de Saxe-Coburgo, irmão de Pedro, o aconselha em relação a possibilidade do terceiro reinado, o qual diz ao irmão “(...) isto não chega para o surdo, nem para o maneta, e muito menos para ti"xxi. A frase e a lucidez de Augusto são invejáveis, pois a sucessão da chefia do governo brasileiro não estava nas mãos do conde d’Eu, nem de seu filho primogênito, mas sim na república. É mister observar a supressão de Isabel na questão sucessória por parte de Augusto, onde esta aparece somente indiretamente e na condição de esposa do "surdo" e de mãe do "maneta", ou seja, figura atrelada aos homens.

No exílio Gaston de Orléans passou definitivamente a estruturar sua vida na Europa, e em 1893 tenta reaver sem sucesso a sua condição de príncipe francês, a qual havia renunciado em 1864 para desposar a princesa herdeira do Brasil. Como não obteve sucesso, este volta a insistir na 
questão em 1901, em carta enviada ao chefe da casa real francesa, o qual responde em setembro do mesmo ano.

\begin{abstract}
Para qualquer família soberana a fidelidade às regras tradicionais é uma condição indispensável de existência. Esta fidelidade é a única segurança de famílias soberanas destituídas. (...) Esta lei existe independentemente da vontade do rei e não cabe a ele criá-la ou modificá-la (...) declaro: O Senhor Conde d'Eu, por ter tomado como residência o Brasil sem o intuito de retornar em 1864, pelos compromissos que o prenderam à coroa brasileira, pela sua renúncia formal aos seus direitos sucessórios quanto à coroa da França, por sua adoção da nacionalidade brasileira, perdeu seus direitos à sucessão da coroa da França e seu status como membro da Família Real da França. Os filhos do Conde d'Eu, nascidos brasileiros de pais brasileiros e dinastas brasileiros, nunca foram príncipes da Casa da França, um status apenas concedido por nascimento e que pode ser perdido mas não ganho. (Fonte: Arquivo Grão-Pará)
\end{abstract}

Mas as questões a serem resolvidas pelo conde d`Eu e sua esposa, que no exílio passara a utilizar o título do marido, estavam para além das questões que envolviam a Casa da França, embora estas estivessem intrinsecamente ligadas. Não era desejável para Luis, o segundo filho dos condes d`Eu um casamento menor, ainda que a monarquia não mais vigorasse em solo brasileiro. A 04 de novembro de 1908 na cidade de Cannes, Luis toma por esposa a princesa Maria Pia de Bourbon-Sicília, filha do chefe da Casa real das Duas-Sicílias, no exílio desde 1861 quando com a unificação italiana. Era esta princesa de casa pobre, exilada e moderado prestígio monárquico, salvaguardada por sua linhagem e posição mandatária de seu pai em caso de restauração monárquica em Nápoles, tinham seus irmãos por consortes a princesa real da Baviera [Wittelsbach], arquiduque da Áustria-Toscana [Habsburgo], e princesa de Saxe [Saxe], três casas ou linhagens que figuravam como parceiras matrimoniais da casa bragantina.

Em carta de 9 de novembro de 1908, a condessa d`Eu, então chefe da Casa imperial do Brasil, nos informa o motivo da relevância da escolha da esposa de Luis, ao se corresponder com os líderes do movimento monárquico no Brasil.

Antes do casamento do Luis assinou ele [Pedro] sua renuncia à coroa do Brasil, e aqui Iha envio, guardando eu papel idêntico. Acho que deve ser publicada esta noticia quanto antes (os senhores queiram fazê-lo da forma que julgarem mais adequada) a fim de evitar-se formação de partidos que seriam um grande mal para nosso país.

Pedro continuará a amar sua pátria e prestará a seu irmão todo o apoio que for necessário e estiver ao seu alcance. Graças a Deus, são muito unidos. Luís ocupar-se-á ativamente de tudo o que disser respeito à monarquia e a qualquer bem para nossa terra. Sem desistir por ora de meus direitos, quero que ele esteja ao fato de tudo, a fim 
de preparar-se para a posição à qual de todo coração desejo que ele chegue. Queiram, pois, escrever-lhe todas as vezes que julgarem necessário, pondo-o a par de tudo o que for dando.

Minhas forças já não são o que eram, mas meu coração é o mesmo para amar a minha pátria e todos aqueles que nos são tão dedicados.

Toda minha amizade e confiança, Isabel, condessa d'Eu.

(BARMAN, 2005, p.303).

Diante a renúncia do primogênito da princesa herdeira do Brasil, "por si e por sua futura descendência" datada de 09 de novembro de 1908, Luis seu irmão, passava a ocupar tal posição. É relevante ressaltar a estratégia adotada pelos Orléans e Bragança, a qual a renúncia de Pedro só é postulada e aceite pela princesa imperial, no exílio, após o casamento em situação de "igualdade de nascimento" de seu filho Luis, o qual tornava-se herdeiro de seus direitos ao trono do Brasil, fato que fornece fortes indicativos para a compreensão do motivo da renúncia de Pedro, o primogênito da princesa.

Isabel ainda revela a preocupação quanto a formação de partidos, tal qual ocorrera com seu sobrinho Pedro de Saxe-Coburgo e Bragança, disputa arrefecida com a república em 1889 e em 1900 com a internação deste em casa de repouso.

No dia 14 de novembro de 1908, Pedro de Orléans e Bragança, desposa a condessa Elisabeth Dobrzensky-Dobrzenicz, membro da baixa nobreza local do império Austro-Húngaro, o qual Pedro tinha por primo o imperador. A desigualdade de nascimento foi a condição sine qua non para a renúncia de Pedro, segundo indicativo da própria princesa Isabel em carta ao Diretório monárquico do Rio de Janeiro, com data de novembro de 1908.

Quero também dar-te a notícia do casamento do nosso filho Pedro. Há mais de cinco anos que ele desejava este consórcio com a Condessa Elisabeth Dobrzensky, de excelente família nobre e antiga. Como porém não era de família régia, demoramos nosso consentimento até que o Luís se casasse, e agora entendemos dever anuir. (BARMAN, 2005 p. 303)

Para os partidários do movimento monárquico brasileiro, que vislumbravam a restauração do regime no país, a renúncia fora precipitada, tanto no entender do visconde de Ouro Preto, um dos líderes do movimento, como no de Corrêa Lima, que escreve a princesa em 1908. 


\begin{abstract}
Se em vez do fato eu tivesse de considerar o projeto, pediria vênia à V.M.I. xxii para insistir no meu parecer de se reservar qualquer intento de renúncia para o tempo da restauração, ou na sua iminência tão segura que não falhasse, ponderando-se então tudo quanto pudesse influir em ato de tanta gravidade (...). Francamente nunca percebi que uma mudança na ordem de sucessão facilitasse o restabelecimento da monarquia, nem que a tal respeito houvesse aqui votos consideráveis e trabalho útil. (VALLON, 2003, p.6)
\end{abstract}

O que Corrêa Lima vislumbrava era o reconhecimento da nulidade do ato da renúncia de Pedro de Orléans e Bragança, para que tal questão fosse apreciada em momento oportuno, por instituições políticas da monarquia quando da sua restauração. O distanciamento de posições entre Isabel e Corrêa, reside no fato da primeira defender a tradição matrimonial de sua família, casa e linhagem, enquanto o segundo, vislumbra questão política, elementos que colaborassem para a restauração da monarquia no país.

Em inúmeras cartas a princesa Isabel faz questão de salientar o casamento de Luís como "(...) ato tão solene da vida de meu sucessor no Trono do Brasil", e que "(...) Luís ocuparceá ativamente de tudo, o que disser respeito a monarquia e a qualquer bem para a nossa terra. Sem desistir por ora de meus direitos, quero que ele esteja ao fato de tudo (...)" deixando claro a sua anuência diante a renúncia de Pedro e a sucessão de Luís na condição de herdeiro do trono.

Se antes da renúncia de Pedro, os condes d’Eu trataram de assegurar um casamento prestigioso ao herdeiros dos direitos brasileiros, o conde d’Eu no início do mesmo ano, 1909 voltou a tratar do que julgava seu direito junto á Casa de Orléans. Em abril de 1909, portanto antes dos consórcios matrimoniais e da renúncia, os membros masculinos de sua Casa se reuniram junto a seu líder em Bruxelas. Não nos é dado saber qual foi o teor da negociação. O resultado foi a Declaração de Bruxelas, redigida com a anuência de todos os presentes.

10. [o conde d’Eu e] seus três filhos, vindos de seu casamento celebrado em 1864, com a Princesa Imperial Isabel, então Herdeira imediata do Trono do Brasil, são membros da Casa Imperial do Brasil e que eles e seus descendentes constituem uma Casa distinta da Casa de Orléans, que compunha a Casa de França. Nos pede reconhecer na França, a estes Príncipes e à sua descendência, masculina, principesca e legítima as Honras dos Príncipes da Casa de França.

Querendo também assegurar, na medida em que o podemos, tanto a qualidade principesca como as Honras de Príncipes da Casa de França.

Reconhecemos aos três filhos do Conde d'Eu e a sua descendência masculina, principesca e legítima os títulos de Príncipes e Princesas de Orléans e Bragança.

40. O Conde d'Eu e seus filhos se comprometem aqui solenemente por si e por sua descendência, a não fazer valer a pretensão à Coroa da França e à posição de Chefe da 
Casa de França, a não ser em caso de extinção total de todos os ramos (...). (Fonte: Arquivo Príncipe do Grão-Pará)

A célula matriz do sistema matrimonial brasileiro é unilateral, mas se abre a possibilidade de se tornar um sistema cognático bilateral em 1864, possibilidade esta reconhecida em 1908 com a Declaração de Bruxelas.

(...) os sistemas cognáticos diferem também dos sistemas unilineares por um segundo aspecto: neles, diacronia e sincronia são, em certa medida, dissociados pela liberdade da escolha que acendem a cada individuo. As sociedades que os possuem, portanto, podem ter acesso à existência histórica, à medida que as flutuações estatísticas, agrupando um grande número de opções individuais, encontram-se por vezes orientadas no mesmo sentido. (LÉVI-STRAUSS, 1986 p.160)

Portanto, o que se coloca é a possibilidade de renúncia à lógica e tradição matrimonial da Casa do Brasil por linhas maternas, embora isso, também, significasse a renúncia dos direitos de herdeiro do Império, mas a preservação do título de príncipe francês, herdado por linhas paternas, uma vez que a Casa da França permitia, em alguns casos, uniões em situação de desigualdade de nascimento, sobretudo de príncipes distantes na linha sucessória, como passava a ser o caso de Pedro de Orléans e Bragança, segundo o quarto artigo da Declaração.

A questão do sistema cognático elaborado por Lévi-Strauss ao estudar sociedades na Indonésia, Polinésia e América, pode nos auxiliar a compreender que a renúncia aos direitos sucessórios ao trono inexistente do Brasil não necessariamente significa uma renúncia à tradição monárquica de modo mais amplo, mas à tradição matrimonial bragantina e suas implicações, portanto, a linhagem materna, uma vez que há a manutenção da titularidade principesca pela ascendência paterna, Orléans, ainda que para tal, seja criada a Casa principesca de Orléans e Bragança, garantindo assim a preservação do status principesco de Pedro, mesmo após a renúncia aos direitos brasileiros.

Mas a questão principesca de Orléans e Bragança estava longe de ser resolvida na primeira década do século XX, uma vez que, se a Casa de Orléans e Bragança fora criada em abril de 1909 e estava subordinada a casa francesa, o casamento de Pedro que ocorreu em novembro do mesmo ano, que não estava mais sob a égide da casa brasileira, diante a sua renúncia, requeria a anuência do chefe da casa francesa para a preservação da titularidade, o qual segundo consta não foi 
consultado, implicando assim na possível perda do título. Os agora príncipes de Orléans e Bragança se articulam em 1910 e respondem ao primo e chefe da casa francesa, sem obter sucesso.

(...) Tendo em vista, além disso, que o Ato [Declaração de Bruxelas] não exigia que os casamentos fossem, propriamente falando, principescos, ou seja, contraídos com pessoas de origem principesca, exigência que, como o mostram os numerosos casos ocorridos nos séculos passados, nunca existiu de direito na Casa de Françaxxiii (MALATIAN, 2010 p.151)

A tensão em 1910 é suscitada pelo Almanach Gotha, respeitada publicação que tratava anualmente genealogias da realeza europeia, informando casamentos, nascimentos e mortes. Quando o chefe da Casa real francesa foi questionado sobre a condição dos príncipes franceses, este indicou que os filhos nascidos da união entre Pedro e Elisabeth, eram frutos de casamento em situação de "desigualdade de nascimento" não conservando e não transmitindo a seus descendentes a condição principesca de Orléans e Bragança.

Neste sentido, Pierre Bourdieu no capitulo "Os usos sociais do parentesco" do livro o Senso Prático, nos coloca questões profundamente próximas e similares a tais elementos.

Todas as estratégias pelas quais os agentes pretendem regularizar-se, e colocar assim a regra de seu lado, estão aí para lembrar que as representações, e em particular as taxinomias de parentesco, têm uma eficácia que, ainda que puramente simbólica, nem por isso é absolutamente menos real. É como instrumento de conhecimento e de construção do mundo social que as estruturas de parentesco desempenham uma função política. (BOURDIEU, 2009 p.280) xxiv $^{-2}$

O reconhecimento da condição principesca de Pedro e sua esposa, garantiria a seus filhos a possibilidade de realizarem casamentos régios, no seio da realeza e nobreza europeia, tal qual a tradição, se não mais da casa bragantina, da casa francesa.

O plano político do conde d’Eu para seus filhos segundo a biografia de sua neta Isabel de Orléans e Bragança ${ }^{x \times v}$, era assegurar a seu primogênito, a posição de príncipe francês, tendo este se casado na simbólica cidade de Versalhes e cabendo como herança o castelo d’Eu, histórica propriedade da família Orléans na Normandia. Ao segundogênito, Luís, herdeiro dos direitos sucessórios da mãe ao trono do Brasil, o casamento se realizou em Cannes, cidade natal da sua esposa, estando ambos em situação de exílio, e impossibilitados de se casarem no Brasil, cabendo a estes por herança a propriedade dos condes d’Eu em Paris. 
A questão principesca de Pedro não se resolve definitivamente até 1926, quando ocorre a morte do então chefe da casa francesa, figurando na publicação do Almanach Gotha a condição principesca de Orléans e Bragança dos filhos deste, nascidos entre 1911 e 1919, graças a interferência e ao prestígio da mãe de Pedro, a princesa Isabel, então chefe da Casa imperial do Brasil, que reconhece a condição principesca de Orléans e Bragança dos netos junto a publicação Gotha, ainda que o título pertencesse a casa francesa e não estivesse sob judice da casa brasileira, gerando dubiedade futura sobre a validade e subordinação do título.

Em 1926 com a ascensão do duque de Guise a chefia da casa francesa, a situação passa a ser favorável a Pedro e seus descendentes no reconhecimento da legitimidade da união e do título por parte da esposa e de seus filhos, a condição de príncipes de Orléans e Bragança. O duque de Guise, diferentemente do duque de Orléans, era mais próximo dos príncipes brasileiros; Guise era neto materno da princesa do Brasil, Francisca de Bragança, tia-avó dos príncipes brasileiros. A esposa do duque de Guise, Isabelle d’Orléans, era cunhada do infante Carlos Tancredi de BourbonSicília, irmão de Maria Pia, esposa de Luís de Orléans e Bragança, irmão de Pedro; e do rei Carlos I de Portugal, primo da condessa d’Eu.

Neste aspecto, com o reconhecimento principesco dos Orléans e Bragança por parte do duque de Guise, ocorre o que Weber denomina por "reconhecimento", como segue no excerto a seguir, em referência a dominação tradicional, em oposição a antiga colocação do duque de Orléans em 1901 em carta ao conde d’Eu.

\footnotetext{
Em princípio, considera-se impossível criar novo direito diante das normas e da tradição. Por conseguinte isso se dá, de fato, através do 'reconhecimento' de um estatuto como 'válido desde sempre' (por 'sabedoria'). Por outro lado, fora das normas tradicionais, a vontade do senhor somente se acha fixada pelos limites que em cada caso lhe põe o sentimento de eqüidade, ou seja, de forma sumamente elástica. Daí a divisão do seu domínio numa área estritamente firmada pela tradição e, em outra, da graça e do arbítrio livres, onde age conforme seu prazer, sua simpatia ou sua antipatia e de acordo com pontos de vista puramente pessoais, sobretudo suscetíveis de se deixarem influenciar por preferências também pessoais.(WEBER, 2006 p.131)
}

Em 1926 as primeiras tratativas do casamento de Isabelle tangenciavam uni-la ao príncipe Afonso de Bourbon-Sicília, infante da Espanha por direito materno e pretendente ao trono Napolitano por direito paterno, em situação cognática tal qual os Orléans e Bragança. Mas o consórcio não se realizou. Na cidade italiana de Palermo, em 1931 Isabel de Orléans e Bragança desposou o príncipe Henri de Orléans, herdeiro do duque de Guise na chefia da casa francesa, 
realizando união endogâmica, prática comum entre os herdeiros Orléans, reconhecendo assim de modo indelével a condição principesca dos filhos do renunciante Pedro de Orléans e Bragança e Elisabeth Dobrzensky de Dobrzenicz.

Este casamento é fundamental para a ramificação primogênita dos Orléans e Bragança, pois ele será o aval da condição principesca dos irmãos de Isabel, que efetuaram casamentos no seio da realeza europeia, elevando o status de prestígio monárquico da família, o qual será usado por seu irmão Pedro Gastão de Orléans e Bragança na busca do reconhecimento da nulidade da renúncia de seu pai em 1908, e dos seus direitos como legítimo herdeiro e sucessor de sua avó, a princesa Isabel ao trono do Brasil.

Após o casamento de Isabel, sua primeira irmã a se casar é Francisca, que desposa em 1942 o pretendente a chefe da casa real portuguesa, Duarte Nuno de Bragança, bisneto do irmão de D. Pedro I do Brasil. Em 1944 Pedro Gastão desposa a irmã menor de Carlos Tancredi de BourbonSicília, e da condessa consorte de Barcelona, mãe do futuro rei Juan Carlos I da Espanha, a infanta Maria Esperança de Bourbon-Sicília.

As uniões matrimoniais dos três filhos mais velhos de Pedro de Orléans e Bragança consolida a presença da família no cenário monárquico europeu, garantindo parentela e relações de proximidades com inúmeras casas reais na Europa, destituídas do poder ou não. No mais, as uniões matrimoniais seguiram o modelo tradicional de alianças da casa bragantina, em condições régias, e portanto de prestígio na França [Orléans] e em Portugal [Bragança], onde seus membros poderiam tornar-se rainhas consorte no caso de restauração da monarquia, e a esposa de Pedro Gastão, irmã do pretendente ao trono das Duas-Sicílias, e tia materna do rei espanhol. O prestígio e a visibilidade estavam garantidos, ainda que diante a existência de um casamento em situação de "desigualdade", legitimado posteriormente pela casa francesa e pela casa brasileira, não na condição de herdeiros do trono do Brasil, mas de príncipes de Orléans e Bragança.

Já da união matrimonial de Luís de Orléans e Bragança e Maria Pia de Bourbon-Sicília, nascem três príncipes entre 1909 e 1913, dos quais apenas dois chegaram a se casar e ter descendência. Mas a morte prematura do príncipe em 1920, impõe algumas vicissitudes a este ramo. O príncipe Luís falece antes de sua mãe, deixando seu filho herdeiro aos 11 anos de idade. Após falecimento de seu pai Pedro Henrique, seu herdeiro foi educado por sua mãe-viúva, Bourbon-Sicília, e tendo por referência masculina seu avô Gastão de Orléans, que vem a falecer em 1922, seu tio paterno, Pedro de Orléans e Bragança em situações esporádicas, mas vivamente 
seu tio materno, Fernando de Bourbon-Sicília pretenso herdeiro do trono napolitano. Este tio era casado com uma princesa da Baviera, o que garante relação de proximidade para a realização em 1940 do casamento de Pedro Henrique com a princesa Maria da Baviera.

No que tange o prestígio, a casa da Baviera já havia figurado entre as parceiras matrimoniais do ramo bragantino brasileiro [segunda esposa de d. Pedro I, Amélia de Leuchtenberg,]. Era a princesa Maria, neta do último rei da Baviera, sobrinha de Fernando de Bourbon-Sicília e de Luis de Saxe-Coburgo e Bragançaxxvi, sobrinho da princesa Isabel do Brasil. Embora o prestígio e a linhagem da noiva fosse inquestionável, a monarquia brasileira tivera relações mais próximas com os latinos portugueses, espanhóis e franceses, os quais o ramo de Pedro de Orléans e Bragança estava ligado pelo casamento de seus filhos, do que a casa alemã da Baviera, sobretudo, em contexto da Segunda Guerra Mundial, ainda que majoritariamente os Wittelsbach tenham feito oposição aos nazistas.

Deste modo, ainda que o prestígio das uniões matrimoniais dos descendentes de Pedro e Luís de Orléans e Bragança sejam próximas e semelhantes, outros elementos se juntam ao discurso e disputa pelo direito de legítima sucessão à tradição e ao trono da Casa do Brasil. Ainda no final dos anos 1930, o príncipe Pedro, se muda para Petrópolis com sua família, fixando residência aos fundos do antigo palácio imperial. A memória do império ainda muito viva nesta cidade do interior fluminence. Na compreensão geral da população, o primogênito da princesa Isabel estava na cidade; suas filhas eram casadas com o "rei" da França, "rei" de Portugal, e seu herdeiro Pedro Gastão era tio do rei da Espanha. Mantendo o prestígio simbólico e imaginário da casa imperial. Para estes, a quebra de uniões matrimoniais em situação de igualdade era pouco relevante, isto é, caso fosse realmente conhecida, afinal, a esposa do príncipe era estrangeira, tal qual uma princesa. Por sua vez, o primogênito e herdeiro de Luís de Orléans e Bragança, apenas se muda para o Brasil com sua família após o final da Segunda Guerra Mundial. Pedro Henrique e sua família se instalam brevemente em Petrópolis, partindo em seguida para Vassouras e, fixando posteriormente residência em fazenda na cidade de Jacarezinho, interior do Paraná, em situação de quase isolamento, onde não circulava com vivacidade os elementos ainda que imaginários e simbólicos da monarquia.

Neste sentido, a principal ferramenta para legitimar a sucessão dos descendentes de Luís ao trono, era a argumentação da renúncia de Pedro em 1908, e o reconhecimento desta por parte da chefe da casa imperial do Brasil, Isabel de Bragança, contado ainda com o casamento desigual 
entre Pedro e Elisabeth, o que significa quebra da tradição monárquica matrimonial brasileira. Por sua vez, no que se referia a argumentação de Pedro Gastão, filho de Pedro de Orléans e Bragança, a renúncia de seu pai, esta não havia sido reconhecida e validada por instituições monárquicas no Brasil, e na ausência destas não poderia ser validada, nem mesmo pela chefe da casa imperial. Ele e suas duas irmãs, haviam realizado casamentos com grandeza régia, bem como suas duas filhas, que desposaram respectivamente o pretendente ao trono da lugoslávia em 1972, e o príncipe polonês de Sapieha-Rozansky em 1980. Alegava ainda, também existir uma quebra nos consórcios matrimoniais dos descendentes de Luís, uma vez que seu neto e herdeiro do trono brasileiro, desposou em 1981 uma princesa sem condição régia, a princesa Cristina de Ligne, ainda que esta fosse filha da princesa Alix de Luxemburgo, prima-irmã do grão-duque reinante de Luxemburgo.

Deste modo, fica claro a relevância o ritual tradicional de consórcios matrimoniais na Casa imperial do Brasil, bem como o uso do prestígio conferido por tais consórcios estrangeiros, na legitimação da condição de herdeiro e sucessor ao trono brasileiro, seja durante o vigor da monarquia na disputa entre as facções Saxe-Coburgo e Bragança versos Orléans e Bragança, seja após a queda do regime na disputa entre Pedro Gastão de Orléans e Bragança e seu primo-irmão Pedro Henrique de Orléans e Bragança, ambos falecidos respectivamente em 2007 e 1981.

Ainda que Pedro Gastão fosse tio de uma cabeça coroada, e cunhado de duas possíveis cabeças coroadas, estes nunca reconheceram abertamente a condição de Pedro Gastão como herdeiro a sucessão do trono brasileiro, ainda que seu livre trânsito e ampla circulação, sobretudo após o casamento dos sobrinhos e sobrinhos-netos nas casas reais da Grécia, Itália, Wurttemberg, Espanha entre outras, somassem ao seu prestígio, enquanto os filhos de Pedro Henrique contavam com o reconhecimento de legitimidade monárquica, mas um prestígio garantido longinquamente pela casa grã-ducal de Luxemburgo, a qual não possui relações diretas com a monarquia brasileira tal qual França, Espanha e Portugal.

O carisma rotinizado continua, assim, a funcionar em favor de todos aqueles cujo poder e posse são garantidos por essa força soberana, e que dependem, portanto, da existência continuada de tal poder.

(WEBER, 1997 p. 138) $)^{\text {xxvii }}$

Deste modo, além da disputa entre os dois ramos descendentes da última princesa imperial do Brasil, a relevância na escolha da consorte do pretenso herdeiro dos direitos 
sucessórios desta, é identificado como elemento chave na estratégia de reconhecimento e legitimação do direito de herança, ainda que no seio do poder simbólico e tradicional, aproximando-se assim em alguma medida dos elementos bourdiezianos e da dominação tradicional de Max Weber, no que tange a rotinização da dominação tradicional.

\section{REFERÊNCIAS}

- $\quad$ ANDERSON, Perry. Linhagens do Estado Absolutista. São Paulo: Brasiliense, 2004.

- $\quad$ BARMAN, Roderick J. Princesa Isabel do Brasil, gênero e poder no século XIX. São Paulo: Ed. UNESP, 2005.

- $\quad$ BOURDIEU, Pierre. O Senso Prático. São Paulo: Vozes, 2009.

- $\quad$ BRAGANÇA, Isabel de Orléans. De todo Coração. Rio de Janeiro: Ed. Francisco Alves, 1983.

- $\quad$ BRAGANÇA, Carlos Tasso de Saxe-Coburgo e. A Intriga. São Paulo: Senac, 2012.

- $\quad$ DEL PRIORE, Mary. O Príncipe Maldito, traição e loucura na família imperial. São Paulo: Ed. Objetiva, 2007. . O Castelo de Papel. Rio de Janeiro: Rocco, 2013.

- $\quad$ HOBSBAWM, Eric. A Invenção das Tradições. São Paulo: Ed. Paz e Terra, 1984.
LÉVI-STRAUSS. Claude. A Via das Mascaras. Lisboa: Presença, 1979.

- RANGEL, Alberto. Gastão de Orléans, o último conde d’Eu. São Paulo: Ed. Cia. Nacional, 1935.

- $\quad$ SARDICA, José Miguel. Terminar a Revolução: A política portuguesa de Napoleão a Salazar.Lisboa: Temas e Debates, 2016.

- $\quad$ SCHWARCZ, Lilia Moritz. As Barbas do Imperador, D. Pedro II, um monarca nos trópicos. São Paulo: Ed. Companhia das Letras, 1998.

- Weber, Max. Weber, Sociologia. Cohn, Gabriel (org.). São Paulo: Editora Ática, 1997.

\section{ARQUIVOS}

- $\quad$ Arquivo do Museu Imperial - Petrópolis (RJ)

- $\quad$ Biblioteca Nacional - Rio de Janeiro (RJ)

\footnotetext{
i STRAUSS, Claude Lévi. Minhas Palavras. São Paulo: Ed. Brasiliense, 1986 p. 185 e 186.

ii ANDERSON, Perry. Linhagens do Estado Absolutista. São Paulo: Brasiliense, 2004.

iii A irmã da consorte do imperador do Brasil, era desde 1823 rainha consorte da Suécia e Noruega, dinastia que ascendeu ao trono sueco após eleição em 1818 do ex-general de Napoleão Bonaparte, João Batista Bernadotte.

iv Dinastia de Wittelsbach.
} 
${ }^{v}$ A princesa mencionada no texto é a princesa Januária de Bragança, filha de Pedro I/ IV de Bragança e de sua primeira esposa Maria Leopoldina de Habsburgo, arquiduquesa da Áustria, filha do imperador Francisco I, logo a princesa Januária era uma neta da Áustria, sendo toda a família imperial austríaca, seus parentes ou primos em primeiro grau, um grau de parentela muito próximo.

vi O príncipe Saxe-Coburgo residia na corte austríaca, onde era tido como príncipe menor, em decorrência do casamento desigual de seus pais; a princesa Januária, era sobrinha do imperador Fernando I da Áustria, o que garantiria a este uma elevação na hierarquia da corte vienense.

vii SCHWARCZ, Lilia Moritz. As Barbas do Imperador, D. Pedro II, um monarca nos trópicos. São Paulo: Ed. Companhia das Letras, 1998.

viii Título reservado ao herdeiro direto do Imperador. Sendo o título de príncipe do Grão-Pará reservado ao herdeiro do príncipe imperial, segundo a Constituição do Império do Brasil de 1824.

ix Francisco de Orléans, era filho do rei Luis Filipe I da França e sua esposa Maria Amélia de Bourbon-Sicília.

${ }^{x}$ Endogamia.

xi Maria II e Fernando II de Portugal eram pais do príncipe Pedro (*1837), herdeiro do trono português [ascende como Pedro V de Portugal]; Luis (1838) [futuro Luis I de Portugal]; João (*1842); Fernando (*1846) e Augusto (*1847). As princesas Isabel e Leopoldina do Brasil haviam nascido respectivamente em 1846 e 1847.

xii (BARMAN, 2006 p.79)

xiii Pierre de Orléans, duque de Penthièvre (*1845).

xiv SARDICA, José Miguel. Terminar a Revolução: A política portuguesa de Napoleão a Salazar.Lisboa: Temas e Debates, 2016.

${ }^{x v}$ Casas como a russa e a prussiana, alternavam em momentos de tendência liberal e conservador.

xvi Arquivo Grão-Pará - Museu Imperial de Petrópolis, consultado em 2012.

xvii Corte de Napoleão III, opositor dos Orléans na França.

xviii Rompimento de relações diplomáticas entre Brasil e Reino Unido, em decorrência da chamada questão Christie.

xix Pedro (*1866); Augusto $(* 1867)$; José $(* 1869)$ e Luis (1870), príncipes de Saxe-Coburgo-Gotha.

${ }^{\mathrm{xx}}$ As possíveis pretendentes eram as princesas Henriete da Bélgica ( $\left.{ }^{*} 1870\right)$, que se casa em 1896 com o primo Emanuel d'Orléans, duque de Vendôme; Helena de Orléans (*1871), sua irmã era casada com o príncipe herdeiro de Portugal [Carlos I], casando-se em 1894 com o duque de Aosta; e Margarida Orléans (*1869), que se casa em 1896 com o filho do ex-presidente da República da França. Era ela neta da princesa Francisca do Brasil.

xxi DEL PRIORE, 2006 p.172.

xxii Vossa Majestade Imperial.

xxiii Embora possa não existir uma lei na Casa Real da França que exigisse um casamento em condições de igualdade de nascimento, não havia na linha ancestral direta dos reis da França [Dinastia Bourbon], um único rei que tivesse realizado casamento desigual, cujo filho tivesse herdado condições régias no reino. Conquanto houvesse inúmeras uniões em segundas e terceiras núpcias, em profunda condição de desigualdade, os frutos de tais uniões recebiam títulos principescos ou de nobreza, embora, ainda assim, sem participação régia. Considerando que a Casa principesca de Orléans e Bragança não era régia, a argumentação se torna plausível.

xxiv BOURDIEU, Pierre. O Senso Prático. São Paulo: Vozes, 2009.

xxv BRAGANÇA, Isabel de Orléans. De todo Coração. Rio de Janeiro: Ed. Francisco Alves, 1983.

xxvi O príncipe Luis, não tinha o Bragança em seu sobrenome ou título. Esta condição foi reservada apenas a seus dois irmãos mais velhos [Pedro e Augusto] que foram educados no Brasil pelo imperador d. Pedro II, após a morte da princesa Leopoldina de Bragança. Para efeitos didáticos e de visualização, acrescentei o apelido Bragança, para evidenciar as relações.

xxvii Weber, Max. Weber, Sociologia. Cohn, Gabriel (org.). São Paulo: Editora Ática, 1997. 